\title{
Xenopus LAP2 $\beta$ protein knockdown affects location of lamin B and nucleoporins and has effect on assembly of cell nucleus and cell viability
}

\author{
Magda Dubińska-Magiera ${ }^{1,2} \cdot$ Magdalena Chmielewska $^{1,3} \cdot$ Katarzyna Koziol $^{1}$. \\ Magdalena Machowska ${ }^{1}$. Christopher J. Hutchison ${ }^{4}$ - Martin W. Goldberg ${ }^{4}$. \\ Ryszard Rzepecki ${ }^{1}$
}

Received: 19 June 2015 / Accepted: 15 July 2015 /Published online: 25 July 2015

(C) The Author(s) 2015. This article is published with open access at Springerlink.com

\begin{abstract}
Xenopus LAP $2 \beta$ protein is the single isoform expressed in XTC cells. The protein localizes on heterochromatin clusters both at the nuclear envelope and inside a cell nucleus. The majority of XLAP $2 \beta$ fraction neither colocalizes with TPX2 protein during interphase nor can be immunoprecipitated with XLAP $2 \beta$ antibody. Knockdown of the XLAP $2 \beta$ protein expression in XTC cells by synthetic siRNA and plasmid encoded siRNA resulted in nuclear abnormalities including changes in shape of nuclei, abnormal chromatin structure, loss of nuclear envelope, mislocalization of integral membrane proteins of INM such as lamin B2, mislocalization of nucleoporins, and cell death. Based on timing of cell death, we suggest mechanism associated with nucleus reassembly or with entry into mitosis. This confirms
\end{abstract}

Handling Editor: Reimer Stick

Magda Dubińska-Magiera, Magdalena Chmielewska, and Katarzyna Kozioł are first joined authors.

Electronic supplementary material The online version of this article (doi:10.1007/s00709-015-0861-y) contains supplementary material, which is available to authorized users.

Ryszard Rzepecki

rzepecki@ibmb.uni.wroc.pl

1 Laboratory of Nuclear Proteins, Faculty of Biotechnology, University of Wrocław, Joliot- Curie 14a, 50-383 Wrocław, Poland

2 Department of Animal Developmental Biology, Institute of Experimental Biology, University of Wroclaw, Sienkiewicza 21, 50-335 Wroclaw, Poland

3 Department of Evolutionary Biology and Vertebrate Conservation, University of Wroclaw, Sienkiewicza 21, 50-335 Wroclaw, Poland

4 Integrative Cell Biology Laboratory, School of Biological and Biomedical Sciences, The University of Durham, South Road, Durham DH1 3LE, UK that Xenopus LAP2 protein is essential for the maintenance of cell nucleus integrity and the process of its reassembly after mitosis.

Keywords LAP2 $\cdot$ Knockdown $\cdot$ Cell nucleus · Nucleoporin $\cdot$ Lamin B $\cdot$ TPX2 $\cdot$ Xenopus laevis

\section{Introduction}

Lamina-associated polypeptide 2 (LAP2) proteins are alternatively spliced proteins belonging to the family of LEM domain proteins (for review, see (Schirmer and Foisner 2007, Dorner et al. 2007, Wagner and Krohne 2007). The LEM domain family in humans was originally composed of three proteins (LAP2, emerin, and MAN1). Since then, four additional LEM domain proteins have been discovered in mammals. These are NET-25 (Lem2), Lem3, Lem4, and Lem5 (Lee and Wilson 2004, Berk et al. 2013). Mutations in genes coding for proteins of the nuclear lamina (also members of a LEM-domain family) lead to laminopathies, a group of rare genetic disorders (for review, see Zaremba-Czogalla et al. 2011a, Dubinska-Magiera et al. 2013).

LAP2 proteins are expressed in metazoans, excluding Caenorhabditis elegans but including Drosophila melanogaster, Danio rerio, Xenopus laevis, Mus musculus, and Homo sapiens. LAP2 proteins are alternatively spliced products of a single gene, resulting in integral membrane or nucleoplasmic (or rarely cytoplasmic) proteins (Harris et al. 1994). Their unique feature is the similar conservative structure, especially among vertebrate orthologues. LAP2 proteins comprise N-terminal "common" domain containing LEM domain and LEM-like domain, both interacting with barrier to autointegration factor (BAF) (Furukawa 1999, Shumaker 
et al. 2001) or DNA (chromatin) (Cai et al. 2001). The rest of the particular LAP2 protein structure and function depends on what exons were incorporated into mature mRNA during alternative splicing of the primary transcript. The "variable" domain typically contains lamin binding domain or specifically lamin B-binding domain and domains responsible for binding to germ-cell-less (GCL) (Nili et al. 2001), HA95 protein (Martins et al. 2003), and histone deacetylase 3 (HDAC3) protein (Somech et al. 2005). Alternative splicing also generates protein isoforms with or without a transmembrane domain. This results in an appearance of integral membrane or "soluble" protein isoform. In mammals, six LAP2 protein isoforms have been discovered $(\alpha, \beta, \gamma, \delta, \varepsilon$, and $\zeta$ ). LAP $2 \alpha$ and LAP2 $\zeta$ proteins lack transmembrane domains and are soluble nucleoplasmic and cytoplasmic proteins, respectively (Shaklai et al. 2008). The most thoroughly studied isoform was mammalian LAP $2 \alpha$ protein due to its ability to modulate signaling pathway associated with Rb protein (LAP $2 \alpha$, lamin $\mathrm{A}, \mathrm{pRb}$ complex) and regulate gene transcription associated inter alia with cell cycle progression into S-phase (Gant et al. 1999, Markiewicz et al. 2002, Yang et al. 1997, Pekovic et al. 2007). Mammalian LAP2 $\beta$ isoforms are also involved in general gene regulation and as transcriptional repressors (Somech et al. 2005). They play a crucial role in attachment of chromatin to the nuclear envelope (NE) and nuclear lamina (NL) during interphase and nuclear reassembly after mitosis.

In X. laevis, there have been five cDNA sequences identified that are presumably translated into three different LAP2 proteins discovered so far, $\omega, \beta$, and $\gamma$ (Gant et al. 1999, Lang et al. 1999, Lang and Krohne 2003, Chmielewska et al. 2011). The Xenopus LAP2 $\beta$ ( $66 \mathrm{kDa}$ somatic polypeptide) is the only one found in adult animals, whereas two other isoforms, $\omega$ and $\gamma(86$ and $40 \mathrm{kDa})$, are present in oocytes and eggs and are downregulated during embryogenesis (Chmielewska et al. 2011). The N-terminal common fragment of XLAP2, when added to the in vitro nuclear assembly reaction, inhibits chromatin decondensation and nuclear growth similarly to the human LAP2 $\beta$ N-terminal fragment (Gant et al. 1999). Moreover, XLAP2 $\beta$ (66 kDa polypeptide) coprecipitates with lamin B2 and A from adult Xenopus tissues and A6 cells (Lang and Krohne 2003). The N-terminal domain of XLAP2 (aa 1-165), like other vertebrate LAPs, interacts with BAF and BAF-DNA complexes. The in vitro interaction of XLAP2 protein isoforms from $X$. laevis egg extracts-XLAP2 $\omega$ and XLAP2 $\gamma$ with a spindle assembly factor-TPX2 (targeting protein for Xklp2) was confirmed. XLAP2-TPX2 complex is therefore thought to be required for proper assembly of postmitotic nuclei in $X$. laevis in vitro nuclear assembly system (O'Brien and Wiese 2006).

Recently, we confirmed the presence of at least three XLAP2 isoforms, $\omega, \beta$, and $\gamma$, that were developmentally regulated (Chmielewska et al. 2011). XLAP2 proteins colocalize with lamin B2 and B3 during development and lamin
B2 in adult tissues. We also demonstrated that Xenopus LAP2 $\beta$ localizes both at the NE and inside the nucleus in clusters of heterochromatin. The intranuclear clusters of XLAP2 $\beta$ on heterochromatin were found to be partly independent of NE invaginations. We also demonstrated that in XTC cells, LAP2 $\beta$ is the sole LAP2 isoform expressed.

In this study, we examined the effect of knockdown of LAP2 $\beta$ protein synthesis in $X$. laevis XTC cells and its effect on cell viability and cell nucleus structure and function.

\section{Materials and methods}

\section{Plasmids, cDNAs and siRNAs, and tissue culture}

Sequences of siRNAs for XLAP2 knockdown were designed using the online Invitrogen tool [https://rnaidesigner. invitrogen.com/rnaiexpress/?CID $=\mathrm{TN}-$ Tools-BlockiT] on the template of XLAP2 clone2 cDNA sequence, AF048815 (Gant et al. 1999): 15 XLAP2 sense strain: 5'- GCAAGA CCCGUCGGUACUUACUAAA -3', 98 XLAP2 sense strain:, 5'- GGAAAGAUGUGUAUGUGCAACUCUA-3', and 237 XLAP2 sense strain, 5'- GAAGACC GACAAACCUAGAGCAGAA-3'. Scrambled control siRNA sequence was: control 15 (c15) sense, 3'GCACCAUGCGGCCAUAUUUCAGAAA-5'.

Xenopus laevis XTC cells (Pudney et al. 1973) were grown in $54 \%$ L-15 Leibovitz medium containing $10 \% \mathrm{FBS}, 2 \mathrm{mM}$ L-glutamine, $10 \mathrm{I} . \mathrm{U} . / \mathrm{ml}$ penicillin, $10 \mu \mathrm{g} / \mathrm{ml}$ streptomycin, and $0.025 \mu \mathrm{g} / \mathrm{ml}$ amphotericin $\mathrm{B}$ at $22-26{ }^{\circ} \mathrm{C}$ in normal air conditions as described previously (Chmielewska et al. 2011).

Cells were transfected with $100 \mathrm{nM}$ specific or control (scrambled) siRNAs using Oligofectamine reagent (Life Technologies). For plasmid-based siRNA knockdown, plasmid pFIV-H1/U6-copGFP (SBI System Bioscience, USA) with inserted sequences of control (C15) and active (15) sequences for siRNA was used. Transfection was with Metafectene Pro (Biontex, Germany) with $1 \mu \mathrm{g}$ of plasmid DNA per $6 \mu \mathrm{l}$ of transfection reagent. Cells were grown on 24-well plates at an initial density of $6 \times 10^{4}$ per well. Cells were collected after $24,48,72$, or $96 \mathrm{~h}$ after transfection, depending on the experiment.

\section{Microscope procedures}

For imaging, confocal microscope LSM 510 META with FCS system was used. For imaging in non-confocal mode, fluorescence microscope (Olympus IX70) was used. Any brightness and contrast adjustments were performed in Adobe Photoshop, Zen 2007 (Zeiss) or ImageJ (Schneider et al. 2012). 


\section{Statistical analysis}

For statistical analyses of cellular phenotypes, the following procedure was used: Samples of XTC cells grown on coverslips were fixed for immunofluorescence microscopy and stained for XLAP2. Ten representative fields from each sample (three independent experiments) were imaged under $\times 10$ objective. In the digital images, the total cell number was counted. The statistical analysis was performed using Statistica software (StatSoft, Poland). Groups of data were compared utilizing the Student's $t$ test. Statistical significance was assumed at values of $P<0.05$. Cell phenotypes were examined in the digital images distinguished on the basis of structural criteria of shape and size of cells and nuclei, organization of microtubular network, cell adherence to the surface, degree of cell shrinking, and apoptotic phenotype (determined by abnormal chromatin condensation, the occurrence of vesicles within the nucleus, and lack of NE staining).

For calculations of number of cells with knockdown XLAP2 protein XTC cells, $48 \mathrm{~h}$ after transfection with plasmid-based siRNA constructs "c15" or "15", were fixed with $4 \%$ paraformaldehyde (PFA), stained with anti-XLAP2 antibody and DAPI, and visualized with confocal microscope. Fifty cells demonstrated GFP expression were counted for each specimen. When counting, the XLAP2 expression level and shape of nuclei were estimated also. Counting was performed for three series of transfections and averaged. Experiments on knockdown of XLAP $2 \beta$ protein (and controls) were always performed simultaneously, exactly at the same session on a confocal microscope. We used the same aliquots of antibodies and the same settings of the microscope. When differences in optical density of the staining were questionable, we performed optical density measurements of NE staining. As a cell with XLAP2 knockdown, we counted cells with an optical density lower than $50 \%$ of a density of control from the same slide. Typically, values for normal NE were about 150 or higher. Random views from slides were selected for observations. For GFP fluorescence (reporter protein for transfection), the threshold was estimated at the background level increased by $100 \%$. Typically, background level was about 20-25 depending on the slide, which means that the threshold was set at 40 to 50 depending on the measured background of currently analyzed slides. Only cells from the same slides were compared. All calculations were made on cells fixed with PFA only since other fixation methods did not preserve the GFP in order to allow reproducible measurements (see Fig. 6).

For calculation of cells number, expressing a detectable level of TPX2 protein, exponentially growing XTC cells were fixed with $4 \%$ PFA, stained with anti-TPX2 antibody and DAPI, and visualized with a confocal microscope. 200 cells were counted. Percentage of cells with the detectable TPX2 signal was calculated, and phases of the cell cycle for those cells were estimated using FACS analyses.

\section{Colocalization studies}

For qualitative colocalization analysis (relative fluorescence intensities measurements), images acquisition were performed on a Zeiss LSM 510 Meta confocal microscope. Distribution of fluorescence intensities along the cross-section of the typical cell was done using "Profile" function of the Zeiss ZEN 2009 software (Carl Zeiss MicroImaging). Resulting graph shows signal intensities in accordance with chosen section (red arrow). To set threshold, point marker (cyan dot or line) was chosen. To show differences in XLAP2 and TPX2 fluorescence intensities in the nuclear envelope, the second point marker (violet dot or line) was set. The calculations for these chosen points are presented in tables.

\section{Quantitative colocalization analysis}

For quantification of colocalization, image acquisition was performed on a Zeiss LSM 510 Meta confocal microscope. Colocalization of proteins' signals was determined using Zeiss ZEN 2009 software (Carl Zeiss MicroImaging). The threshold was set for each pair of channels by selecting region of interest (ROI) outside the cells. Subsequently, the ROIs at the intranuclear area, at the nuclear envelope, or in the cytoplasm were chosen, and colocalizations were calculated. For each case, five ROIs, coming from separate cells, were analyzed. Finally, averaged calculations, graphs, and statistical analysis were done based on percentage of signals from lamin B2 channel that are colocalized with signals from XLAP2 and TPX2 in the analyzed ROI and is insensitive to differences in signal intensities.

\section{Antibodies, immunofluorescence, and Western blotting}

For immunofluorescence (IF), XTC cells were grown on coverslips, fixed with $4 \%$ PFA in phosphate buffered saline (PBS) for $15 \mathrm{~min}$, permeabilized with $0.5 \%$ Triton X-100 in PBS $(v / v)$ for $5 \mathrm{~min}$, and blocked with $1 \%$ fetal bovine serum (FBS) in PBS (for $30 \mathrm{~min}$ at room temperature). Alternatively, to use selected antibodies, cells were fixed with ice-cold methanol for $10 \mathrm{~min}$ in $-20{ }^{\circ} \mathrm{C}$ without separated permeabilization step. All wash steps were done with PBS. Primary antibodies were used for overnight incubation at $4{ }^{\circ} \mathrm{C}$ and secondary antibodies for $60 \mathrm{~min}$ at room temperature. DNA was stained with DAPI (4,6-diamidino-2-phenylindole, $0.2 \mu \mathrm{g} / \mathrm{ml}$ in mounting medium with Mowiol, and DABCO). For imaging, confocal microscope LSM 510 META with FCS system was used. Any brightness and contrast adjustments were 

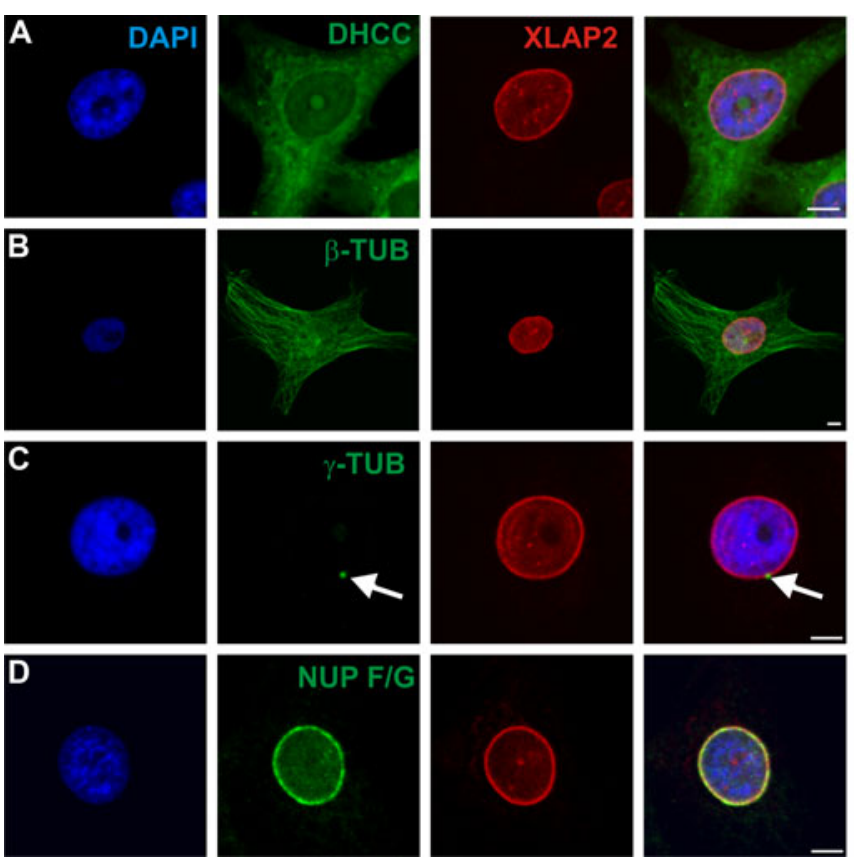

Fig. 1 XLAP2 $\beta$ localizes in X. laevis XTC cells typically for the inner nuclear membrane protein. Cells were grown on coverslips, fixed with PFA or methanol, and stained for XLAP2 $\beta$, lamin B2, nucleoporins F/G, XBAF, TPX2, actin, $\gamma$-tubulin, $\beta$-tubulin, and membranes (DHCC). DNA was visualized with DAPI (blue). Single confocal sections $(1.5 \mu \mathrm{m})$ through the center of nuclei are shown. Bar: $5 \mu \mathrm{m}$. Interphase XLAP $2 \beta$ protein colocalizes with lamin B2, shows apparent

performed in Adobe Photoshop, Zen 2007 (Zeiss) or ImageJ (Schneider et al. 2012).

The specific serum and antibodies for an N-terminal fragment of XLAP2 protein were produced as described previously (Rzepecki et al. 1998).

The following antibodies were used: rabbit affinity purified anti-N-TPX2 antibody (1:100 IF) was a kind gift from Prof. Y. Zheng (Tsai et al. 2006), antibodies anti-XBAF protein (1:50 IF) were from Prof. P.A. Fisher and Prof. K. Furukawa (Dechat et al. 2004, Furukawa et al. 2003), and affinity purified IgGs: anti-XLAP2 (1:100 WB, 1:60 IF) (Salpingidou et al. 2008, Chmielewska et al. 2011). Mouse monoclonal antibodies: anti- $X$. laevis lamin B2 ab (1:25 IF, Santa Cruz Biotechnology sc-56147), Ab 414 against nucleoporins with F/G repeats (1:100 IF, Covance MMS-120P), Ac-40 actin Ab (1:800 WB, Sigma), rat monoclonals anti-alpha-tubulin YL1/ 2 (1:60, Serotec), anti- $\beta$-tubulin (1:150 IF, Sigma T4026), and anti- $\gamma$-tubulin (1:100 IF, Sigma T5326). For F-actin identification, Alexa Fluor ${ }^{\circledR} 546$ phalloidin was used (at a concentration of $2 \mathrm{U} / \mathrm{ml}$; Invitrogen). Cellular lipid membranes were stained with DHCC (3,3"-dihexyloxacarbocyanine iodide at a concentration of $7.5 \mu \mathrm{g} / \mathrm{ml}$; Invitrogen). Secondary antibodies for immunoblotting and fluorescence were from Jacksons ImmunoResearch.

Proteins were separated on 10 or $12 \%$ SDS-PAGE gels and electro-transferred onto nitrocellulose filters. For XLAP2
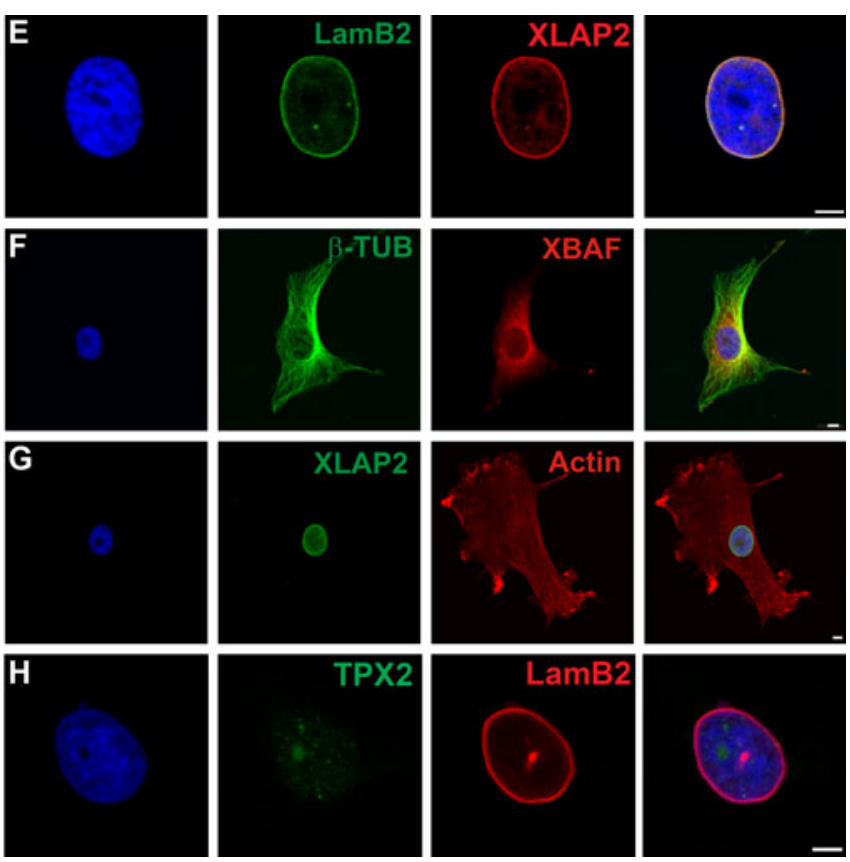

colocalization with FG-repeat nucleoporins, and partly colocalizes with BAF proteins at the NE only. LAP2 $\beta$ does not localize to cytoplasm or ER. In XTC cells, centrosomes locate immediately next to NE. XTC cells show a fibroblast-like distribution of microtubules and actin. In interphase XTC cells, TPX2 protein is weakly expressed. It gradually appears in the mid-S phase and is dispersed through the whole nucleoplasm so does not colocalize with XLAP2 $\beta$

silencing analyses, optical density measurements of the protein bands in immunoblots were performed with the BIOPROFIL Bio-1D Windows Application V99.01. Protein content in protein bands was normalized according to the actin content in each lane. Western blotting analysis of the XLAP2 protein silencing in XTC cells was monitored by staining with antibodies against XLAP2 and actin staining with $\mathrm{mAb}$ to beta actin (AC-40, SIGMA) was used as loading control. Optical density of XLAP2 and actin bands was measured with the BIO-PROFIL Bio-1D Windows Application V99.01, and XLAP2 content was normalized versus actin for each lane.

\section{Immunoprecipitation and mass spectroscopy}

Immunoprecipitation (IP) and mass spectroscopy (MS) were performed essentially as described previously (Rzepecki et al. 1998, Chmielewska et al. 2011, Zaremba-Czogalla et al. 2011b) with minor modifications. All co-IP experiments were performed under native conditions under different ionic strength in order to extract fractions of XLAP $2 \beta$ protein with different solubility. Co-IP procedure number 1 was performed with extraction, binding and washing the beads with buffer containing $0.3 \mathrm{M} \mathrm{NaCl}$. The procedure number 2 was performed with $0.6 \mathrm{M} \mathrm{NaCl}$ and procedure number 3 with $0.6 \mathrm{M} \mathrm{NaCl}$ in extraction buffer and $0.3 \mathrm{M} \mathrm{NaCl}$ during the rest of the procedure. For each co-IP procedure, we used $9 \times$ 

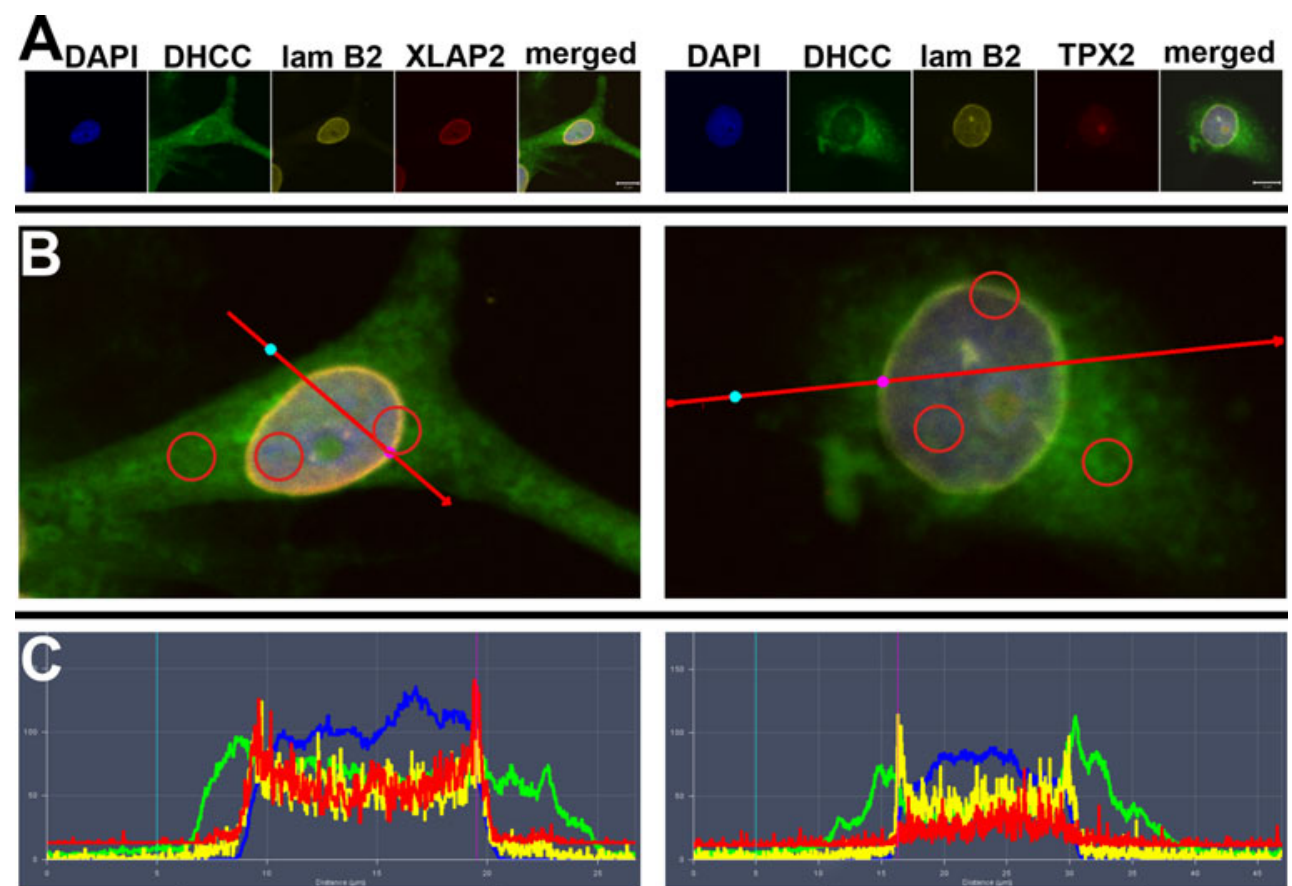

\begin{tabular}{|l|c|c|c|}
\hline intensity & left marker & right marker & differrence \\
\hline DAPI & 0 & 82 & 82 \\
membranes & 10 & 75 & 65 \\
\hline lamin B2 & 3 & 101 & 98 \\
\hline XLAP2 & 13 & 125 & 112 \\
\hline
\end{tabular}

\begin{tabular}{|l|c|c|c|}
\hline intensity & left marker & right marker & differrence \\
\hline DAPI & 0 & 31 & 31 \\
\hline membranes & 6 & 51 & 45 \\
\hline lamin B2 & 4 & 114 & 110 \\
\hline TPX2 & 11 & 20 & 9 \\
\hline
\end{tabular}

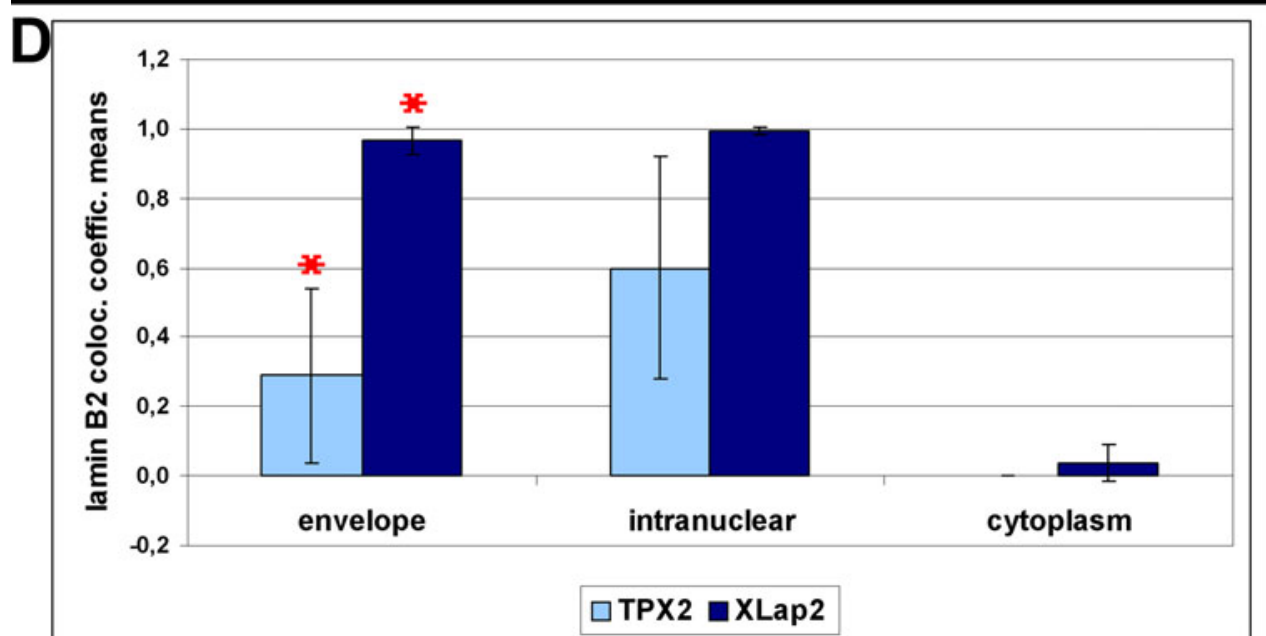

Fig. 2 The main fraction of XLAP2 $\beta$ does not colocalize with TPX2 in XTC cells during interphase. XTC cells were grown on coverslips, fixed with methanol, and stained for XLAP2 $\beta$, lamin B2, TPX2, and membranes (DHCC). DNA was visualized with DAPI (blue). Single confocal sections $(1.5 \mu \mathrm{m})$ through the center of nuclei are shown in $\mathbf{a}$. Bar: $10 \mu \mathrm{m}$. They illustrate typical localization for those antigens in XTC cells. For TPX2 localization and all analyses of its colocalization, only cells with high level (easily detectable) of TPX2 were chosen. b Line sections (long red arrows) used for qualitative colocalization analyses (relative fluorescence intensities distribution). c Results of these analyses. Left marker (cyan) indicates point outside the cell (threshold) and right marker (violet) points the nuclear envelope. It is clearly seen that
TPX2 does not localize to nuclear envelope where the main signal from XLAP2 locates. b Presents three type of regions of the cell (intranuclear, envelope, and cytoplasm), shown as red circles, which were the basis for quantitative colocalization calculations resulted in the graph displayed in d. Bars of the chart indicate colocalization coefficients of lamin B2 with XLAP2 either TPX2. Red asterisks show statistically significant differences between analyzed colocalizations. Lamin B2 colocalizes with XLAP2 in the nuclear envelope and in the nuclear interior but only partially with TPX2. In the envelope, the difference between colocalization coefficients for XLAP2 and for TPX2 is statistically significant, and inside the nucleus is on the borderline of significance. Hence, TPX2 and XLAP2 do not colocalize in examined regions 
$10^{6}$ cells, and for Western blot analyses, equivalents of $2 \times 10^{5}$ cells/lane were loaded. Only proteins with "identification score" of $100 \%$ in at least one IP procedure were shown.

\section{Mass spectrometry}

For identification of coimmunoprecipitated proteins, tandem mass spectrometry was conducted essentially as described previously (Chmielewska et al. 2011, Zaremba-Czogalla et al. 2011b).

\section{Results}

\section{Localization of XLAP2 $\beta$ in cultured XTC cells during interphase}

In order to get an insight into the cell cycle-dependent localization of XLAP $2 \beta$ in comparison to other important cellular proteins, we used XTC cells that express this single isoform and have a fibroblast-like phenotype (Chmielewska et al. 2011).

Interphase XLAP2 $\beta$ protein shows typical location for integral protein of inner nuclear membrane (INM), colocalizes with lamin B2, shows apparent colocalization with FG-repeat nucleoporins, and does not localize to cytoplasm or endoplasmic reticulum (ER) (Fig. 1). Centrosomes (MTOCs) locate immediately next to NE in XTC cells. BAF protein is distributed at the NE and surrounding cytoplasm. LAP $2 \beta$ partly colocalizes only with BAF protein at the NE. Please note that XTC cells show a fibroblast-like distribution of microtubules and actin (Fig. 1).

We also analyzed the distribution of TPX2 protein in interphase XTC cells (Fig. 1) due to the previous report that XLAP2 $\omega$ and $\gamma$ proteins interact with TPX2 protein from Xenopus egg extracts (O'Brien and Wiese 2006). We found that most of XTC cells demonstrated weak or no staining with anti-TPX2 antibodies (Additional file 1: Figure S1B). TPX2 protein is distributed through the nuclear interior. Detailed analyses revealed that only about $40 \%$ of interphase cells demonstrate clearly detectable by immunofluorescence staining, higher level of TPX2 protein and that the location of the protein is intranuclear (Additional file 1: Figure S1). The analyses of the cell cycle in XTC cells using FACS method indicated that this $40 \%$ of cells correlates roughly with a percentage of cells in S-phase together with G2/M-phase (not shown). This feature of frog TPX2 reflects the behavior of mammalian TPX2 protein (Stewart and Fang 2005). Since our XLAP2 $\beta$ antibody and TPX2 antibody were raised in rabbits, we could not perform direct colocalization studies between these two proteins. That is why we used indirect approach and studied XLAP $2 \beta$ and TPX 2 protein colocalization with lamin B2 and analyzed the distribution of these proteins through the nuclear
Fig. 3 Analysis of the XLAP2 protein knockdown in tissue cultured $X$. laevis XTC cells. XTC cells were plated at $7.5 \times 10^{4}$ cells/well, transfected with $100 \mathrm{nM}$ siRNA sequences, and grown for 24 and $72 \mathrm{~h}$. C-XTC, untreated cells; 15, 98, 237xlap, cells treated with different siRNAs. a Schematic diagram of the Xenopus LAP $2 \beta$ protein. The positions of amino acid residues are marked above the diagram. Locations of predicted domains are marked by different patterns: striped box common domain of all potential isoforms, white box LEM domain, hatched box the transmembrane region. cDNA sequences given below the diagram were used to design $25 \mathrm{nt}$ ds siRNAs for XLAP2 protein expression silencing. Numbers denote a position of nucleotides. b Western blotting analysis of the XLAP2 protein silencing in tissue cultured $X$. laevis XTC cells after 24 and $72 \mathrm{~h}$ post- transfection. Equal amounts of the protein were loaded. Numbers denoted above each lane represent the relative amounts of XLAP2 protein. Molecular masses of the proteins $(\mathrm{kDa})$ are marked on the left side of the picture. XLAP2 knockdown was most efficient with 98xlap and 15xlap siRNAs after 3 days post-transfection. c, d Effect of XLAP2 protein knockdown on the morphology of XTC cells was also analyzed by confocal and immunofluorescence microscopy. XTC cells were stained for XLAP2 (red), DNA was visualized with DAPI (blue). $\mathbf{c}$ General view of the control, non-treated, and siRNA transfected XTC cells. Note the complete loss of XLAP2 signal after $72 \mathrm{~h}$ post-transfection with 15xlap siRNA. d Higher magnification of the control and silenced nuclei imaged in non-confocal (3 left columns) or confocal mode (right column) visualize that the degrading XLAP2 protein is no longer localized in the NE. DNA is amorphous (98xlap). Note the apoptotic nucleus with lobulations (15xlap lower photograph). Images were combined and processed in Adobe Photoshop. Single confocal sections $(1.5 \mu \mathrm{m})$ through the center of nuclei are shown. Bars, $20 \mu \mathrm{m}$ (c), $10 \mu \mathrm{m}$ (d)

compartment. Figure 2a demonstrates typical example for staining of XTC cells for DNA, membranes, XLAP2, TPX2, and lamin B2. Figure $2 b$ demonstrates merged images with line sections taken for fluorescence intensities analyses shown in Fig. 2c. Figure 2b also indicates a marked different type of regions used for calculation of colocalization coefficients illustrated in Fig. 2d. The demonstrated data indicate that there is no significant fraction of XLAP2 $\beta$ and TPX2 protein colocalizing with each other, particularly at the nuclear envelope location where, additionally, it localizes only residual fraction of TPX2. This suggests that major fractions of both proteins may not interact with each other.

In order to detect potential interactions between XLAP2 and TPX2 proteins, we used immunoprecipitation for XLAP2 followed by mass spectroscopy for identification of coimmunoprecipitated proteins from unsynchronized XTC cell extracts. The results of such experiments performed under three different ionic conditions are demonstrated in Additional file 2: Figure S2. TPX2 protein was not detected in any of the samples with XLAP2 $\beta$ co-immunoprecipitated proteins. Also, our previous studies on XLAP $2 \beta$ protein using IP and mass spectrometry did not show TPX2 as an interacting partner (Chmielewska et al. 2011) (22). Thus, our data indicate that most of Xenopus TPX2 do not colocalize with the majority of LAP $2 \beta$ in XTC cells during interphase. This means that 

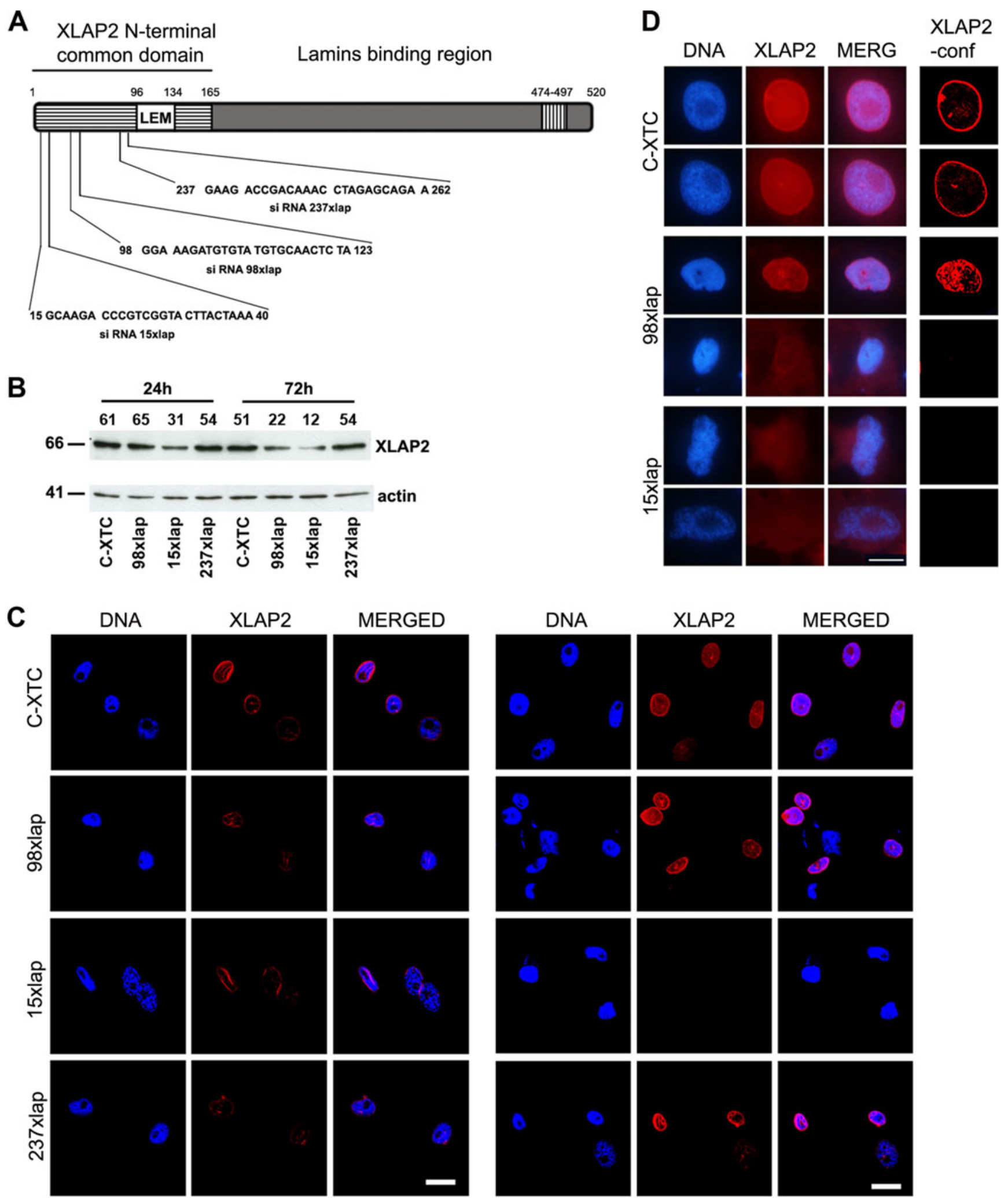

$24 \mathrm{~h}$

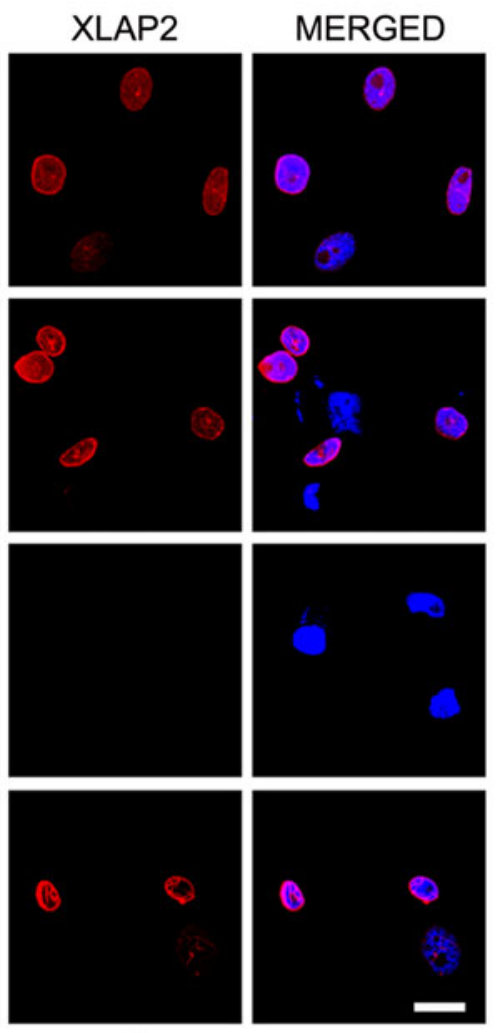

$72 \mathrm{~h}$ 

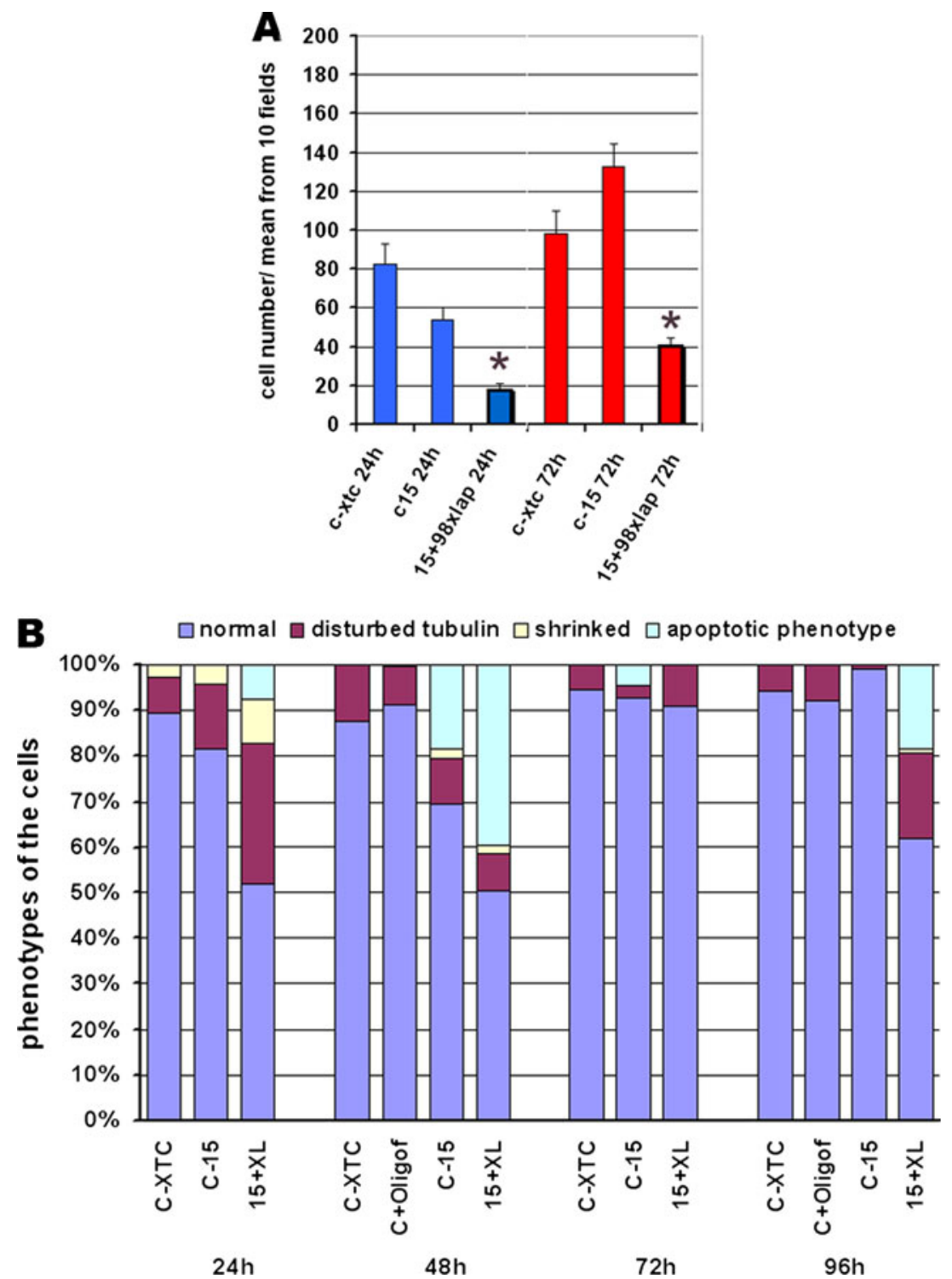

Fig. 4 Microscopic immunofluorescence analyses of XTC cells subjected to knockdown or mock-knockdown procedures. Knockdown of XLAP2 protein in XTC cells results in inhibition of growth, increased cell death and cellular abnormalities. a, b Tissue cultured cells were grown on glass coverslips and transfected either with 15XLAP2 and 98XLAP2 siRNAs or scrambled control siRNA (C-15). Untreated cells (C-XTC) were used as a control. After the indicated period of time, cells were fixed and costained for XLAP2 and $\alpha$-tubulin and DNA was visualized with DAPI (not shown). a Cells from 10 representative fields were counted. The diagram represents total cell count from 10 fields.

Asterisk denotes statistically significant lower cell number in $15+$ 98xlap siRNA treated XTC cells versus c15 siRNA control cells $(P<0.05)$. b Analysis of cellular organization in XTC cells from 10 fields. Normal, well-organized tubular network, average nucleus size; disturbed tubulin, cells showing partially condensed tubulin but attached to the surface, small nucleus; shrinked, condensed tubulin, small nucleus; apoptotic phenotype, weak or no tubulin staining, no NE staining, degraded DNA. XLAP2 knockdown results in phenotype abnormalities in XTC cells, as well as in cell death

$\mathrm{XLAP} 2 \beta$ protein (unlike XLAP $2 \omega$ and $\gamma$ ) is not responsible for TPX2 protein retention in cell nucleus during interphase.

\section{siRNA mediated knockdown of XLAP2 $\beta$ results in nuclear and cellular abnormalities and cell death}

In order to unveil the cellular function of LAP $2 \beta$ protein in $X$. laevis, we used siRNA to knockdown the expression of a single XLAP $2 \beta$ isoform present in XTC cells. Figure 3 shows a schematic diagram of the protein, sequences of the siRNA fragments, their location in N-terminal "common domain," and the results of the knockdown experiment. The most efficient knockdown effect, as assayed by Western blot, showed 15xlap siRNA ( $80 \%$ ) and the lesser 98xlap (64\%), while 237xlap siRNA showed no effect (Fig. 3b). Similar data were obtained by IF and confocal analyses, where it was possible to 
observe the decreased level of XLAP2 protein (Fig. 3c, 237lap, 98lap) or its apparent disappearance after $72 \mathrm{~h}$ (Fig. 3c, 15xlap). Detailed analyses of the cell nuclei revealed almost complete loss of the XLAP2 protein from the NE in cells treated with $15 x$ xlap siRNA. This was associated with the nuclear shape abnormalities (Fig. 3d), similar to lamin A/C knockout fibroblasts or EDMD (Emery-Dreifuss muscular dystrophy) patients (Sullivan et al. 1999).

Subsequent large-scale analyses of the siRNA transfected cells revealed the toxic effect of the XLAP2 protein knockdown and a drastically decreased growth of XTC cultures. Figure 4 demonstrates the representative results of one series of such experiments. When cell number was analyzed (Fig. 4a), we clearly observed the toxic effect of XLAP2 knockdown on XTC cells after 24 and $72 \mathrm{~h}$ comparing to control cells and control siRNA treatment. The analyses of the cell phenotypes after XLAP2 knockdown also demonstrated increased percentage of the cell shape abnormalities (Fig. 4b). Cells treated with siRNA had increased a percentage of apoptotic phenotype, were shrinked, and/or had disturbed microtubule network.

Based on the analyses of cells still attached to cover glass at the time of observation (Fig. 4), the first visible effect to appear (after $24 \mathrm{~h}$ ) is the disturbed cytoskeleton and shrinking of the cells with only a fraction of cells with apoptotic phenotype.

At $48 \mathrm{~h}$, almost exactly the same number of cells showed abnormal phenotype, but most of them were apoptotic. Similar temporal effect of the appearance of abnormal and apoptotic phenotype is observed in the cycle between 72 and $96 \mathrm{~h}$ (Fig. 4) but obscured by proliferating normal (nontransfected) cells (Fig. 4a).

Based on the fact that we have detected only a few mitotic cells with LAP2 knockdown, we may conclude that, in general, knockdown of XLAP2 $\beta$ in XTC cells either stops the cells from entry into mitosis or cells detach themselves from the surface of culture vessel/cover glass before mitotic entry or both. We propose that this effect is the result of abnormal nucleus re-assembly when cells lack XLAP $2 \beta$ protein.

\section{XLAP2 $\beta$ knockdown affect cell nuclei morphology and location of lamin $B 2$ and nucleoporins}

Xenopus XTC cells are not easy to transfect; therefore, in most of our experiments, we could not get sufficient efficiency of transfection for detailed studies of cell cycle or pathways affected using bulk tissue culture transfection. Due to the toxicity of XLAP2 $\beta$ knockdown, we were unable to select stable cell line with constitutive protein knockdown as well.

Therefore, in order to perform knockdown experiments in more controllable system allowing for easy detection of transfected cells under microscope, presumably with decreased level of XLAP $2 \beta$ protein, we switched to plasmid- based siRNA transfection system (pFIV-H1/U6-copGFP) with GFP (green fluorescent protein) reporter protein as a marker for transfected cells. Plasmid encoded siRNA system due to the GFP reporter protein expression makes available the distinction of the particular transfected cell for study. Additionally, when possible, the level and distribution of XLAP2 protein were visualized. Thus, we were able to monitor the knockdown effect in transfected cells only (Fig. 5) and monitor the level and location of XLAP2 $\beta$ protein together with other proteins in multichannel confocal microscopy.

Data indicated that although control siRNA has some minor effect on cell morphology, and XLAP $2 \beta$ protein was distributed in more diffused (partly nucleoplasmic) pattern than in non-transfected cells, only antisense siRNA was able to knockdown XLAP2 protein expression. This correlated with the abnormal nuclear shape and atypical chromatin staining (Fig. 5).

Statistical analyses of cells with GFP for expression of XLAP2 $\beta$ protein using confocal microscopy demonstrated that there is a very good correlation between GFP expression and decreased level of XLAP2 $\beta$ in cells transfected with the silencing construct. Eighty-six percent of cells expressing GFP showed decreased level of XLAP $2 \beta$, and this downregulation, in $80 \%$ of cases, was associated with the abnormal phenotype of nuclei (Additional file 3: Figure S3).

Typical nuclear abnormalities most frequently observed in cells with decreased level of XLAP2 $\beta$ protein were demonstrated in details in Additional file 4: Figure S4. The cells with decreased level of LAP $2 \beta$ protein exhibited changed shape of cell nuclei and FG-repeat nucleoporins relocation into the nucleoplasm. Nuclear pore complexes (NPCs) form clusters, frequently elongated or forming lines (Additional file 4: Figure S4). Cells with low level of XLAP2 $\beta$ also showed discontinuous rim-like staining of the NE and NL and had typically abnormal shape and chromatin distribution similar to those observed in cells from EDMD patients (laminopathy of a muscular dystrophy type) (Fig. 5 and Additional file 4: Figure S4). During analyses of hundreds of XTC cells using this knockdown system, we also did not observe mitotic cells with decreased level of LAP $2 \beta$ protein.

Detailed analyses of the effect of XLAP $2 \beta$ protein knockdown on the distribution of selected proteins during interphase are demonstrated in Figure 6. It is shown that in XTC cells with decreased level of XLAP2 $\beta$ protein, both FG-repeat nucleoporins and lamin B2 protein were redistributed. In case of FG-repeat nucleoporins, changes in their distribution consist in the loss of its regular rim-like pattern in favor of linelike or granular-like pattern with proteins diffused throughout the nucleoplasm. LAP2 $\beta$ knockdown resulted in abnormal location of lamin B2. Typically, lamin B2 and NPCs were absent from peripheral region of one side of cell nucleus (Additional file 4: Figure S4). Microtubule network was also frequently affected, but we did not find any statistical correlation 


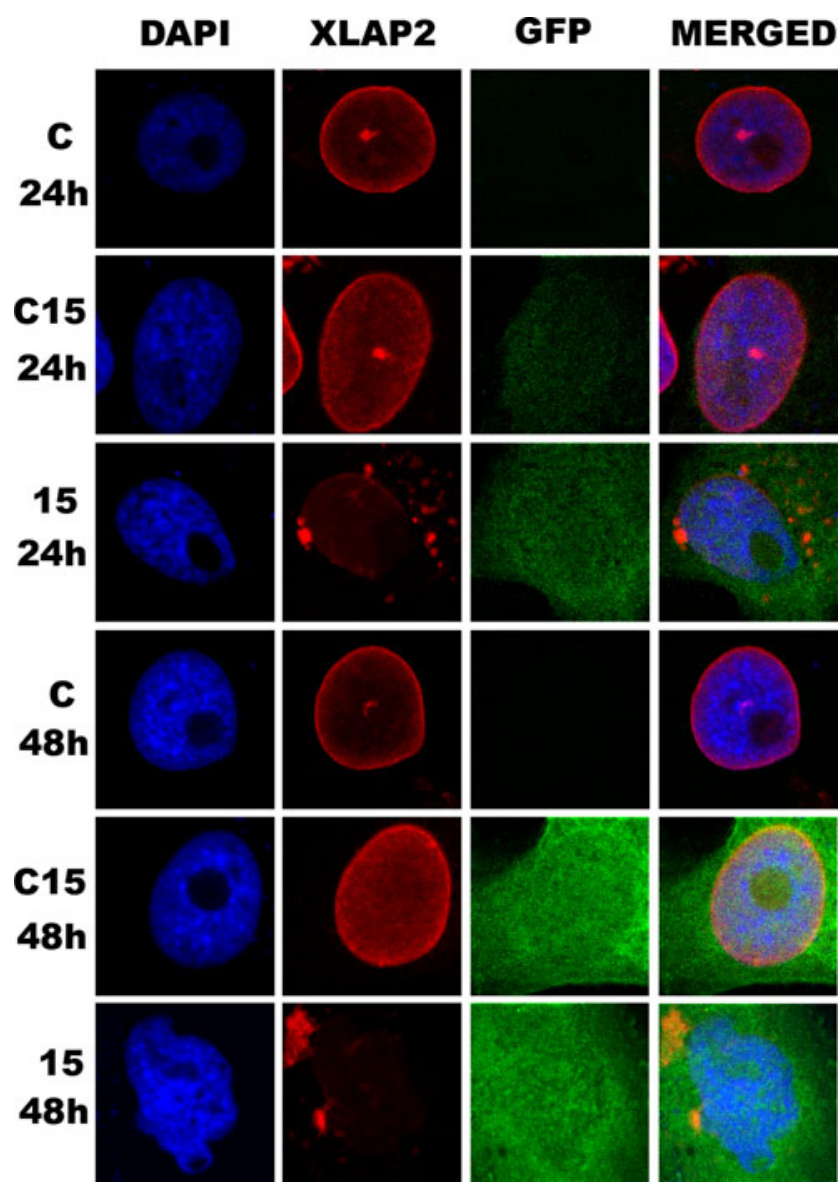

Fig. 5 Knockdown of XLAP $2 \beta$ in tissue cultured $X$. laevis XTC cells results in cell abnormalities. XTC cells were transfected with plasmid encoding antisense (15) or scrambled (C15) siRNA together with GFP as a transfection marker directed against an $\mathrm{N}$-terminal fragment of XLAP2. For immunofluorescence, cells were grown on glass coverslips for 24 or $48 \mathrm{~h}$ after transfection, fixed in PFA, and stained for XLAP2 (red) and DNA (DAPI, blue), GFP (green). Single confocal sections $(1.5 \mu \mathrm{m})$ through the center of nuclei are shown. Bar: $5 \mu \mathrm{m}$. Untreated cells $(C)$ or cells treated with a plasmid encoding scrambled siRNA and GFP (C15) were used as controls. Note that nuclear shape abnormalities are concomitant with loss of XLAP2 protein from NE. Note XLAP2 speckles and discontinuous XLAP2 in NE in nucleus transfected with 15 siRNA plasmid after $24 \mathrm{~h}$ and lobular shape of apoptotic nucleus after $48 \mathrm{~h}$

between XLAP2 $\beta$ knockdown and location and distance of centrosomes to the NE.

\section{Discussion}

\section{XLAP2 distribution in XTC cells and question of TPX2}

Our data demonstrated that XLAP2 $\beta$ protein localizes mostly to the NE of XTC cells during interphase. During this phase, XLAP2 colocalizes with typical NE and NL antigens as lamin B2 (Fig. 1a). Apparent colocalization with nucleoporins (Fig. 1a) does not indicate their interaction. Higher resolution images (STED) or SEM/TEM studies demonstrated that they
Fig. 6 XLAP2 $\beta$ knockdown affects cell nuclei morphology and interferes with the proper location of lamin B2 and nucleoporins. XTC cells were transfected with siRNA plasmid, encoding silencing (15) or scrambled (C15) siRNA with GFP as a transfection marker, directed against an N-terminal fragment of XLAP2. For immunofluorescence, cells were grown on coverslips for $48 \mathrm{~h}$ after transfection, fixed with PFA or methanol, and stained for XLAP2 $\beta$ (red), DNA (blue), and nucleoporins with $\mathrm{F} / \mathrm{G}$ repeats, lamin $\mathrm{B} 2, \beta$ - and $\gamma$-tubulin (yellow). Expressed GFP proteins (green) localize throughout the whole cell volume. For most images, GFP looks precipitated and weakly visible because of methanol fixation method used to obtain the best performance of individual antibodies. Single confocal sections $(1.5 \mu \mathrm{m})$ through the center of nuclei are shown. Bar: $5 \mu \mathrm{m}$. XTC cells with decreased level of XLAP $2 \beta$ protein have abnormally shaped nuclei, and F/G-repeat nucleoporins and lamin B2 are redistributed. The microtubule network is frequently shrunk, but centrosomes remain their normal position directly at the nuclei

do not colocalize (Chmielewska et al. 2011). There is no significant colocalization between most of XLAP2 and TPX2 protein during interphase (Fig. 2) particularly at the nuclear envelope. Also, TPX2 protein does not interact with XLAP2 protein as revealed by our co-IP experiments (Additional file 2: Figure S2) on XTC cells. This documents that XLAP2 $\beta$ protein does not colocalize nor interact with TPX2 protein during interphase as XLAP $2 \omega$ and $\gamma$ isoforms do in frog egg extract (O'Brien and Wiese 2006). This suggests that XLAP2 $\beta$ isoform shows different properties in this respect than isoforms $\gamma$ and $\omega$ which are present in mature $X$. laevis eggs (Chmielewska et al. 2011). This can be simply accounted for different exon composition between $\beta$ and $\omega$ and $\gamma$ isoforms.

\section{Knockdown of XLAP2 and cell death mechanisms}

XTC cells, besides A6 cells, are the only well characterized $X$. laevis cells available for studies in tissue cultured cells model. Both cell types are difficult to transfect, but XTC cells seem to offer a small advantage of giving higher efficiency of transfection (up to $50 \%$ typically). This makes impossible to perform whole cell culture studies (Western blot analyses of signaling pathways, etc.). Our attempts to isolate transfected or transduced cells using FACS and GFP reporter protein, using pFIV-H1/U6-copGFP based constructs and virus, failed because the expression of reporter protein was simultaneous with expression of siRNA that was toxic and resulted in detachment of cells with decreased XLAP2 protein synthesis. Subsequently, our attempt to select stable cell lines with inducible expression of siRNA failed probably due to the inefficient switching off of the promoter for siRNA. Thus, our experimental procedures were limited to confocal microscopy analyses of cells with reporter protein-GFP marking transfected cells. There was a very good correlation between GFP expression and knockdown of XLAP2 protein (Additional file 3: Figure S3), so we adopted this method for all subsequent studies. 
Xenopus LAP 2 $\beta$ protein knockdown

953

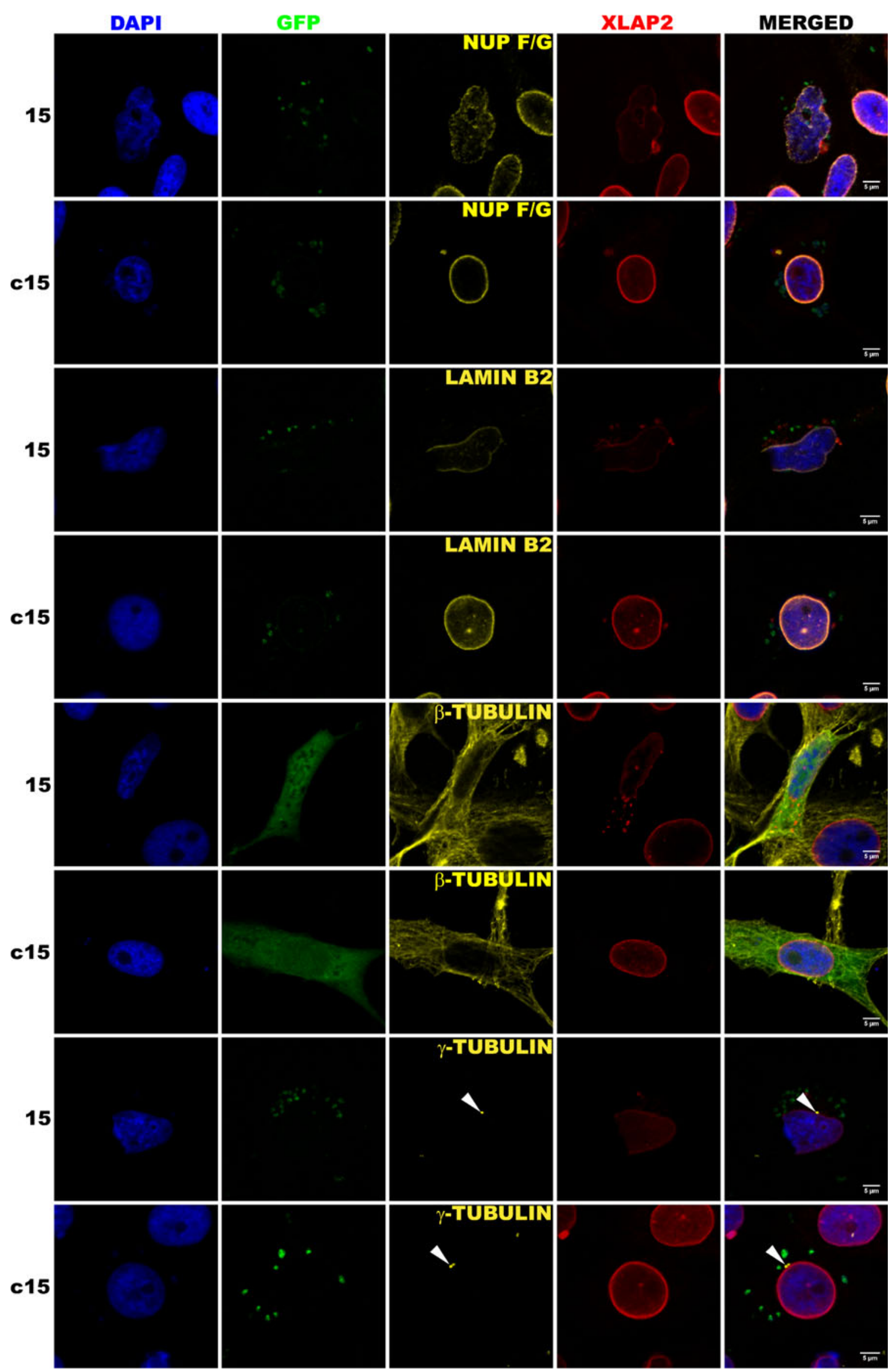

Springer 
We observed that cells with decreasing levels of XLAP2 $\beta$ protein gradually accumulated abnormalities in size, shape, and microtubule network (Fig. 4, Additional file 4: Figure S4), leading finally to cell detachment from the surface. These changes were accompanied by changes in chromatin and nuclear morphology, NE structure, and distribution of nuclear and NPC proteins (Figs. 5 and 6). A surprising feature of cells with a low level of XLAP $2 \beta$ was that we could not detect mitotic cells. This suggests that lack of LAP $2 \beta$ prevents cells from mitotic entry or that abnormally re-assembled nuclei (and chromatin) in such cells resulted in cell cycle block at G0/G1 or G1/S/G2. The major effect of XLAP2 $\beta$ knockdown was structural abnormalities of the cells, which were followed by appearance of apoptotic phenotype. This would favor the hypothesis that apoptosis is a secondary effect of XLAP2 $\beta$ knockdown in XTC cells.

Since isoform $\beta$ is the only LAP2 protein in XTC cells, this may account for the severity of knockdown phenotype though there may be several plausible mechanisms involved. In $X$. laevis, at least three different isoforms were detected during development (Chmielewska et al. 2011). Since they share several common domains, some of the functions may be conserved between them. Domains with no similarity between them may be responsible for different properties, unique for particular isoform. XLAP2 $\beta$ was found to be associated with clusters of heterochromatin both next to NE and internally in cell nuclei. As we have previously shown, XLAP2 $\beta$ was present inside the cell nucleus both in nuclear envelope invaginations and without visible nuclear membranes in interphase cells (Chmielewska et al. 2011). Since mammalian LAP2 $\beta$ interacts with HDAC3 (Somech et al. 2005), this protein may be anchored on heterochromatin by Xenopus LAP $2 \beta$ protein and, thus, maintain the inactive status of heterochromatin. The knockdown of XLAP2 $\beta$ may result in the release of HDAC 3 from heterochromatin loci and change in location and transcription activity, or both. Similar results were shown for lamin B receptor (LBR), inner nuclear membrane protein responsible for heterochromatin positioning at nuclear periphery, present in NE, and membrane invaginations inside the cell nucleus (Ellenberg et al. 1997). Knockdown of LBR by morpholino antisense nucleotides in 1-2 cell zebrafish embryos caused reduced viability and severe morphological alterations in surviving embryos (Schild-Prufert et al. 2006). RNAi-mediated knockdown of LBR in HeLa cells resulted in failure of NE reassembly and abnormal chromatin decondensation after mitosis leading to the apoptotic cell death ( $\mathrm{Lu}$ et al. 2010). On the other hand, disruption of LBR function in differentiating cells was responsible for the loss of peripheral heterochromatin and inverted nuclear morphology with heterochromatin present in nuclear interior, which in turn altered gene expression profile (Solovei et al. 2013).

Mechanism that may function during mitosis is associated with the structural role of LAP $2 \beta$ protein in the maintenance of nuclear structure and reassembly during mitosis. The lack of XLAP $2 \beta$ - LEM domain integral membrane of INM and loss of one of the links between chromatin and NE (chromatin-BAF-LAP2 $\beta$ at NE) may result in abnormal nucleus and NE reassembly observed in our studies (Figs. 5 and 6). Since in Xenopus cells, many different LEM domain proteins are expressed besides LAP $2 \beta$, the severity of phenotype is lower than LBR knockdown.

Proper assembly of lamin B and nucleoporins is necessary for DNA replication, transcription, and nuclear pore spacing. Defects in their distribution affect all these processes (Smythe et al. 2000, Moir et al. 2000, Spann et al. 2002, Margalit et al. 2005). XLAP2 $\beta$ knockdown disrupts lamin B2 and NPC protein location at NE and NL, which in turn can affect these processes. On top of the above mechanisms lack of LAP $2 \beta$ leads to the redistribution of lamin B2 and probably the relocation of lamin A since both proteins interact with LAP2 proteins. This may further enhance the above mechanisms that finally results in the cells death after XLAP2 $\beta$ expression knockdown.

Acknowledgments We would like to thank Prof. P.A. Fisher and Prof. K. Furukawa for anti-BAF antibodies and Prof. Y. Zheng for rabbit anti TPX2 antibodies. This work was partially supported by grants: European Social Fund, Lower Silesia Research Grants for PhD students and Erasmus training fellowship to M. Ch. and M. D-M. This work was partially supported by the Polish Ministry of Science and Higher Education Statutory Grant (1013/S/WB/2011-2013), Wrocław Research Center EIT+ under the project: Biotechnologies and Advanced Medical Technologies BioMed (POIG.01.01.02-02-003/08) and COST Action BM1002 Nanonet: Nanomechanics of Intermediate Filament Network (R.R.). Publication costs were partially covered by Wroclaw Centre of Biotechnology, programme The Leading National Research Centre (KNOW) for years 2014-2018.

Conflict of interests The authors declare that they have no conflict of interests.

Open Access This article is distributed under the terms of the Creative Commons Attribution 4.0 International License (http:// creativecommons.org/licenses/by/4.0/), which permits unrestricted use, distribution, and reproduction in any medium, provided you give appropriate credit to the original author(s) and the source, provide a link to the Creative Commons license, and indicate if changes were made.

\section{References}

Berk JM, Tifft KE, Wilson KL (2013) The nuclear envelope LEMdomain protein emerin. Nucleus 4(4):298-314. doi:10.4161/nucl. 25751

Cai M, Huang Y, Ghirlando R, Wilson KL, Craigie R, Clore GM (2001) Solution structure of the constant region of nuclear envelope protein LAP2 reveals two LEM-domain structures: one binds BAF and the other binds DNA. EMBO J 20(16):4399-4407. doi:10.1093/emboj/ 20.16.4399 
Chmielewska M, Dubinska-Magiera M, Sopel M, Rzepecka D, Hutchison CJ, Goldberg MW, Rzepecki R (2011) Embryonic and adult isoforms of XLAP2 form microdomains associated with chromatin and the nuclear envelope. Cell Tissue Res 344(1):97-110. doi: 10.1007/s00441-011-1129-2

Dechat T, Gajewski A, Korbei B, Gerlich D, Daigle N, Haraguchi T, Furukawa K, Ellenberg J, Foisner R (2004) LAP2alpha and BAF transiently localize to telomeres and specific regions on chromatin during nuclear assembly. J Cell Sci 117(Pt 25):6117-6128. doi:10. $1242 /$ jcs. 01529

Dorner D, Gotzmann J, Foisner R (2007) Nucleoplasmic lamins and their interaction partners, LAP2alpha, Rb, and BAF, in transcriptional regulation. FEBS J 274(6):1362-1373

Dubinska-Magiera M, Zaremba-Czogalla M, Rzepecki R (2013) Muscle development, regeneration and laminopathies: how lamins or lamina-associated proteins can contribute to muscle development, regeneration and disease. Cell Mol Life Sci 70(15):2713-2741. doi: 10.1007/s00018-012-1190-3

Ellenberg J, Siggia ED, Moreira JE, Smith CL, Presley JF, Worman HJ, Lippincott-Schwartz J (1997) Nuclear membrane dynamics and reassembly in living cells: targeting of an inner nuclear membrane protein in interphase and mitosis. J Cell Biol 138(6):1193-1206

Furukawa K (1999) LAP2 binding protein 1 (L2BP1/BAF) is a candidate mediator of LAP2-chromatin interaction. J Cell Sci 112(Pt 15): 2485-2492

Furukawa K, Sugiyama S, Osouda S, Goto H, Inagaki M, Horigome T, Omata S, McConnell M, Fisher PA, Nishida Y (2003) Barrier-toautointegration factor plays crucial roles in cell cycle progression and nuclear organization in Drosophila. J Cell Sci 116(Pt 18):38113823. doi: $10.1242 /$ jcs.00682

Gant TM, Harris CA, Wilson KL (1999) Roles of LAP2 proteins in nuclear assembly and DNA replication: truncated LAP2beta proteins alter lamina assembly, envelope formation, nuclear size, and DNA replication efficiency in Xenopus laevis extracts. J Cell Biol 144(6):1083-1096

Harris CA, Andryuk PJ, Cline S, Chan HK, Natarajan A, Siekierka JJ, Goldstein G (1994) Three distinct human thymopoietins are derived from alternatively spliced mRNAs. Proc Natl Acad Sci U S A 91(14):6283-6287

Lang C, Krohne G (2003) Lamina-associated polypeptide 2beta (LAP2beta) is contained in a protein complex together with Aand B-type lamins. Eur J Cell Biol 82(3):143-153

Lang C, Paulin-Levasseur M, Gajewski A, Alsheimer M, Benavente R, Krohne G (1999) Molecular characterization and developmentally regulated expression of Xenopus lamina-associated polypeptide 2 (XLAP2). J Cell Sci 112(Pt 5):749-759

Lee KK, Wilson KL (2004) All in the family: evidence for four new LEM-domain proteins Lem2 (NET-25), Lem3, Lem4 and Lem5 in the human genome. Symp Soc Exp Biol 56:329-339

Lu X, Shi Y, Lu Q, Ma Y, Luo J, Wang Q, Ji J, Jiang Q, Zhang C (2010) Requirement for lamin B receptor and its regulation by importin \{beta\} and phosphorylation in nuclear envelope assembly during mitotic exit. J Biol Chem 285(43):33281-33293. doi:10.1074/jbc. M110.102368

Margalit A, Vlcek S, Gruenbaum Y, Foisner R (2005) Breaking and making of the nuclear envelope. J Cell Biochem 95(3):454-465. doi: $10.1002 /$ jcb. 20433

Markiewicz E, Dechat T, Foisner R, Quinlan RA, Hutchison CJ (2002) Lamin $\mathrm{A} / \mathrm{C}$ binding protein LAP2alpha is required for nuclear anchorage of retinoblastoma protein. Mol Biol Cell 13(12):44014413. doi:10.1091/mbc.E02-07-0450

Martins S, Eikvar S, Furukawa K, Collas P (2003) HA95 and LAP2 beta mediate a novel chromatin-nuclear envelope interaction implicated in initiation of DNA replication. J Cell Biol 160(2):177-188. doi:10. 1083/jcb.200210026
Moir RD, Spann TP, Herrmann H, Goldman RD (2000) Disruption of nuclear lamin organization blocks the elongation phase of DNA replication. J Cell Biol 149(6):1179-1192

Nili E, Cojocaru GS, Kalma Y, Ginsberg D, Copeland NG, Gilbert DJ, Jenkins NA, Berger R, Shaklai S, Amariglio N, Brok-Simoni F, Simon AJ, Rechavi G (2001) Nuclear membrane protein LAP2beta mediates transcriptional repression alone and together with its binding partner GCL (germ-cell-less). J Cell Sci 114(Pt 18):3297-3307

O'Brien LL, Wiese C (2006) TPX2 is required for postmitotic nuclear assembly in cell-free Xenopus laevis egg extracts. J Cell Biol 173(5):685-694. doi:10.1083/jcb.200512107

Pekovic V, Harborth J, Broers JL, Ramaekers FC, van Engelen B, Lammens $\mathrm{M}$, von Zglinicki T, Foisner R, Hutchison C, Markiewicz E (2007) Nucleoplasmic LAP2alpha-lamin A complexes are required to maintain a proliferative state in human fibroblasts. J Cell Biol 176(2):163-172. doi:10.1083/jcb.200606139

Pudney M, Varma MG, Leake CJ (1973) Establishment of a cell line (XTC-2) from the South African clawed toad, Xenopus laevis. Experientia 29(4):466-467

Rzepecki R, Bogachev SS, Kokoza E, Stuurman N, Fisher PA (1998) In vivo association of lamins with nucleic acids in Drosophila melanogaster. J Cell Sci 111(Pt 1):121-129

Salpingidou G, Rzepecki R, Kiseleva E, Lyon C, Lane B, Fusiek K, Golebiewska A, Drummond S, Allen T, Ellis JA, Smythe C, Goldberg MW, Hutchison CJ (2008) NEP-A and NEP-B both contribute to nuclear pore formation in Xenopus eggs and oocytes. J Cell Sci 121(Pt 5):706-716. doi:10.1242/jcs.019968

Schild-Prufert K, Giegerich M, Schafer M, Winkler C, Krohne G (2006) Structural and functional characterization of the zebrafish lamin B receptor. Eur J Cell Biol 85(8):813-824. doi:10.1016/j.ejcb.2006. 04.009, S0171-9335(06)00079-3

Schirmer EC, Foisner R (2007) Proteins that associate with lamins: many faces, many functions. Exp Cell Res 313(10):2167-2179. doi:10. 1016/j.yexcr.2007.03.012, S0014-4827(07)00120-6

Schneider CA, Rasband WS, Eliceiri KW (2012) NIH Image to ImageJ: 25 years of image analysis. Nat Methods 9(7):671-675

Shaklai S, Somech R, Gal-Yam EN, Deshet-Unger N, MoshitchMoshkovitz S, Hirschberg K, Amariglio N, Simon AJ, Rechavi G (2008) LAP2zeta binds BAF and suppresses LAP2beta-mediated transcriptional repression. Eur J Cell Biol 87(5):267-278. doi:10. 1016/j.ejcb.2008.01.014, S0171-9335(08)00040-X

Shumaker DK, Lee KK, Tanhehco YC, Craigie R, Wilson KL (2001) LAP2 binds to BAF.DNA complexes: requirement for the LEM domain and modulation by variable regions. EMBO J 20(7):1754 1764. doi:10.1093/emboj/20.7.1754

Smythe C, Jenkins HE, Hutchison CJ (2000) Incorporation of the nuclear pore basket protein nup153 into nuclear pore structures is dependent upon lamina assembly: evidence from cell-free extracts of Xenopus eggs. EMBO J 19(15):3918-3931. doi:10.1093/emboj/19.15.3918

Solovei I, Wang AS, Thanisch K, Schmidt CS, Krebs S, Zwerger M, Cohen TV, Devys D, Foisner R, Peichl L, Herrmann H, Blum H, Engelkamp D, Stewart CL, Leonhardt H, Joffe B (2013) LBR and lamin $\mathrm{A} / \mathrm{C}$ sequentially tether peripheral heterochromatin and inversely regulate differentiation. Cell 152(3):584-598. doi:10.1016/ j.cell.2013.01.009, S0092-8674(13)00012-3

Somech R, Shaklai S, Geller O, Amariglio N, Simon AJ, Rechavi G, GalYam EN (2005) The nuclear-envelope protein and transcriptional repressor LAP2beta interacts with HDAC3 at the nuclear periphery, and induces histone H4 deacetylation. J Cell Sci 118(Pt 17):40174025. doi: $10.1242 /$ jes. $02521, \mathbf{1 1 8} / \mathbf{1 7} / \mathbf{4 0 1 7}$

Spann TP, Goldman AE, Wang C, Huang S, Goldman RD (2002) Alteration of nuclear lamin organization inhibits RNA polymerase II-dependent transcription. J Cell Biol 156(4):603-608. doi:10. 1083/jcb.200112047 
Stewart S, Fang G (2005) Anaphase-promoting complex/cyclosome controls the stability of TPX2 during mitotic exit. Mol Cell Biol 25(23): 10516-10527. doi:10.1128/MCB.25.23.10516-10527.2005

Sullivan T, Escalante-Alcalde D, Bhatt H, Anver M, Bhat N, Nagashima K, Stewart CL, Burke B (1999) Loss of A-type lamin expression compromises nuclear envelope integrity leading to muscular dystrophy. J Cell Biol 147(5):913-920

Tsai MY, Wang S, Heidinger JM, Shumaker DK, Adam SA, Goldman RD, Zheng Y (2006) A mitotic lamin B matrix induced by RanGTP required for spindle assembly. Science 311(5769):1887-1893. doi: $10.1126 /$ science. 1122771

Wagner N, Krohne G (2007) LEM-Domain proteins: new insights into lamin-interacting proteins. Int Rev Cytol 261:1-46. doi:10.1016/ S0074-7696(07)61001-8
Yang L, Guan T, Gerace L (1997) Lamin-binding fragment of LAP2 inhibits increase in nuclear volume during the cell cycle and progression into S phase. J Cell Biol 139(5):1077-1087

Zaremba-Czogalla M, Dubinska-Magiera M, Rzepecki R (2011a) Laminopathies: the molecular background of the disease and the prospects for its treatment. Cell Mol Biol Lett 16(1):114-148. doi: 10.2478/s11658-010-0038-9

Zaremba-Czogalla M, Gagat P, Koziol K, Dubinska-Magiera M, Sikora J, Dadlez M, Rzepecki R (2011b) Identification of new in vivo phosphosites on lamin Dm-the evidence of heterogeneity of phosphorylation sites in different Drosophila tissues. Nucleus 2(5):478-488. doi:10.4161/nucl. 2.5.17864 